\title{
Cost of Illness of Epilepsy and Associated Factors in Patients Attending Adult Outpatient Department of University of Gondar Referral Hospital, Northwest Ethiopia
}

\author{
Piniel Melkamu' \\ Yaregal Animut ${ }^{2}$ \\ Amare Minyihun (iD ${ }^{3}$ \\ Asmamaw Atnafu (1D ${ }^{3}$ \\ Mezgebu Yitayal $\mathbb{D}^{3}$ \\ 'University of Gondar Specialized \\ Referral Hospital, Gondar, Ethiopia; \\ ${ }^{2}$ Department of Epidemiology and \\ Biostatistics, Institute of Public Health, \\ College of Medicine and Health Sciences, \\ University of Gondar, Gondar, Ethiopia; \\ ${ }^{3}$ Department of Health Systems and \\ Policy, Institute of Public Health, College \\ of Medicine and Health Sciences, \\ University of Gondar, Gondar, Ethiopia
}

\begin{abstract}
Background: Epilepsy has significant economic implications on health care needs, premature death, and lost work productivity. Therefore, this study aimed to assess the cost of illness of epilepsy and its associated factors in the Outpatient Department of University of Gondar Referral Hospital, Northwest Ethiopia.

Methods: We conducted an institution-based cross-sectional study from March 2018 to April 2018. A total of 442 adult epileptic patients were selected from the chronic follow-up clinic using a systematic sampling technique. We fitted binary logistic regression to identify the associated factors, and significant variables in the multivariable logistic regression analysis were determined using P-value $<0.05$ and $95 \% \mathrm{CI}$.

Results: The study revealed that the mean total cost illness of epilepsy per patient per year was US\$ $166 \pm 61.6$, and $30.3 \%$ of patients incurred high cost. Age (AOR $=1.06 ; 95 \% \mathrm{CI}$ : $1.03,1.09)$, $\operatorname{sex}(\mathrm{AOR}=3.66 ; 95 \% \mathrm{CI}: 1.94,6.89)$, educational $(\mathrm{AOR}=0.15 ; 95 \% \mathrm{CI}: 0.005$, $0.047)$, polytherapy $(\mathrm{AOR}=4.66 ; 95 \% \mathrm{CI}: 2.29,9.46)$, seizure frequency $(\mathrm{AOR}=4.48 ; 95 \%$ CI: $1.56,12.8)$, place where AEDs were bought $(\mathrm{AOR}=6.23 ; 95 \% \mathrm{CI}: 2.7,14.03)$ and disease duration $(\mathrm{AOR}=0.11 ; 95 \% \mathrm{CI}: 0.05,0.25)$ were predictors of the cost of illness of epilepsy.

Conclusion: The total annual cost of illness of epilepsy was high, taking into account the per capita income of the individuals. The age, sex, and educational status of the patients, and the number of AED, seizure frequency, places where patients buy drugs, and disease duration were factors significantly associated with the cost of illness of epilepsy. Hence, creating an alternative source of income, socio-economic support, and affordable health care service for patients, especially for female and elderly patients, and strengthening and equipping nearby clinics, increasing drug availability in governmental pharmacies.
\end{abstract}

Keywords: cost of illness, epilepsy, University of Gondar Referral Hospital, Northwest Ethiopia

\section{Background}

Epilepsy is the most common neurological disorder characterized by recurrent (two or more) epileptic unprovoked seizure disorders that affect people of all ages and socioeconomic classes worldwide. ${ }^{1}$ Among 50 million people with Epilepsy, an estimated 40 million people live in developing countries. ${ }^{2}$ Epilepsy is one of the 20 leading causes of mortality in Ethiopia, with a prevalence rate of 5.2 per 1000 people. Its ever-
Correspondence: Mezgebu Yitay Department of Health Systems and Policy, Institute of Public Health, College of Medicine and Health Sciences, University of Gondar, P.O. Box 196, Gondar, Ethiopia Tel +25I 947057683

Email mezgebuy@gmail.com 
increasing prevalence could cause significant harm to the well-being of individuals and society as a whole.

Epilepsy results in high economic costs due to treatment, productivity loss, and increased health care utilization. ${ }^{3}$ It has significant long-term socio-economic consequences and high personal health care costs, especially in low- and middle-income countries. ${ }^{1}$ Estimates suggest that some countries spend as much as one percent of their total national health care expenditure on epilepsy care and treatment. ${ }^{4,5}$ Patients with Epilepsy have significantly higher rates of health-related contacts and medication use and a higher socio-economic cost, lower employment rates, and income. ${ }^{5-9}$ People with Epilepsy reported the highest productivity losses and unemployment.

Epilepsy is associated with enormous direct and indirect costs in developed ${ }^{10,11}$ and developing ${ }^{12}$ countries. In Africa, the cost for Epilepsy per person per year varies from US\$ 11 in Burundi to US\$ 1157 in Nigeria. ${ }^{13,14}$ A study conducted in Ethiopia, which assesses the burden of medical impoverishment due to out-of-pocket direct medical costs, ranks Epilepsy as the 17th disease pushing households below the poverty line. ${ }^{15}$ The costs of Epilepsy vary by age, sex, marital status, family size, educational status, residence, employment status, distance from the health facility, seizure-related injuries, frequency of seizure, duration of illness, and poly-therapy. ${ }^{6,16-18}$

Evidence shows that socio-demographic and economic factors such as age, sex, marital status, education, employment, family size, wealth, and distance from the health facility are factors associated with the cost of illness of Epilepsy. A study in Oman indicates age as a significant predictor, which shows a positive relationship with the cost of Epilepsy. The total cost increases as the patient grew older. ${ }^{19}$ A study conducted in China also shows an increasing trend of cost of Epilepsy with older age. Religion, ethnicity, and marital status are found insignificant in most studies. Besides, most studies concur that high cost does not seem to link with gender. ${ }^{20,21}$ A study in Bhutan ${ }^{21}$ also shows a significant association of long-distance from residence to clinic with the high cost of Epilepsy.

Frequency of seizure, number of antiepileptic drugs taken, and duration of illness are some of the disease-related factors that affect the cost of Epilepsy. Seizure frequencies were the most commonly reported predictor, and increased seizure frequency was positively associated with cost. ${ }^{16,17,22}$

However, studies in Ethiopia have focused on morbidity and mortality of Epilepsy and have not assessed the economic impact of Epilepsy. Therefore, this study aimed to estimate the cost of illness of Epilepsy and its associated factors in patients attending the adult Outpatient Department of the University of Gondar Referral Hospital (UoGRH), Northwest Ethiopia.

\section{Methods}

\section{Study Design and Area}

We conducted an institution-based cross-sectional quantitative study from March 2018 to April 2018 at the UoGRH. The UoGRH is one of the tertiary health care facilities in Ethiopia and the Amhara region, and it serves more than five million people in the catchment area. The hospital has 09 outpatient departments and 14 inpatient wards with 550 beds. It has an outpatient epilepsy clinic that functions two days a week with a patient flow of around 800 patients per month.

\section{Study Population and Sampling}

The study population was all adult epileptic patients who came to the outpatient department during the study period at the UoGRH. We included all adult epilepsy patients with $<1$ year of the study's follow-up period and excluded epilepsy patients with other chronic illnesses, such as diabetes mellitus and heart failure from the survey.

We used a formula of single population proportion to determine the sample size. We based the computation on the $95 \%$ confidence interval $(\mathrm{Z} \alpha / 2=1.96), 5 \%$ marginal error (d), and $50 \%$ of epilepsy patients who incur a high cost (p) and a $15 \%$ non-response rate.

$$
\mathrm{n}=\mathrm{Z}_{\alpha / 2}{ }^{2} \mathrm{P}(1-\mathrm{P}) / \mathrm{d}^{2}=(1.96)^{2}(0.50)(0.50) /(0.05)^{2}
$$
$=384$

By adding 15\%, $\mathrm{n}=384+15 / 100(384)=442$ epilepsy patients were the final sample size.

We obtained the sample population from the Epilepsy clinic at the UoGRH. We included all epileptic patients who started follow-up before April 2017. We used systematic random sampling to select the study participants. On average, every month, around 800 adult epileptic patients came to the outpatient clinic. Therefore, the interval $(\mathrm{k}$ ) was determined by dividing $800 / 442$. The first patient was selected using the lottery method from the first two patients, and then every other eligible epileptic patient was selected and interviewed.

\section{Data Collection Procedures}

We used a structured questionnaire to assess the cost of Epilepsy. Participants provided self-reports of the number 
of visits to and payments for OPD clinic, the number of days and a daily fee of outpatient visits, cost of medications, cost of diagnostic tests performed, cost of round trip transportations, cost of food and accommodation, cost of traditional medicine or other alternative therapies and days of work missed by patients as well as family members because of caring for an individual with Epilepsy. We asked participants to recall these health expenditures over the prior year. Trained health professionals (six BSC Nurses), who received 2-days training on the objective, methods, questionnaires, and ethics of the study, collected the data. One week before the actual data collection period, we conducted a pre-test in Bahir Dar Felege Hiwot Referral Hospital on 21 patients. We assessed the questionnaire for its completeness, clarity, and length. We performed daily supervision during data collection, and data were double-entered to minimize errors during data processing.

\section{Operational Definitions Direct Cost}

It refers to prices of goods and services incurred for epilepsy treatment which include medical expenses such as cost of medicine, lab tests and investigations, consultation fees, and non-medical costs like transportation, food, and accommodation.

\section{Indirect Cost}

It refers to the monetary value of lost output due to a patient's reduced productivity due to morbidity. We employed the human capital method to measure the indirect cost of Epilepsy which is a method of estimating the potential indirect costs based on the loss of workdays, leading to an inability to work for the patients. These workdays were changed into monetary terms using the wage the patients have been earning.

\section{Total Cost}

It is the sum of direct and indirect costs. We scored the costs as high and low by calculating the total cost incurred for the Epilepsy treatment from their annual income. The cost incurred was categorized as high cost if the total cost incurred was higher than or equal to $40 \%$ of yearly income; and low cost, if the total cost incurred, was less than $40 \%$ of annual income. ${ }^{23}$

\section{Data Processing and Analysis}

The collected data were cleaned, coded, and entered into EPI INFO version 7 and exported to SPSS version 20 for analysis. We used descriptive statistics such as frequency distribution, mean, and SD to present the data's characteristics. We used binary logistic regression to identify factors associated with the cost of illness of Epilepsy. We considered variables for the final model (multivariable logistic regression analysis) if they were significant at a p-value of $\leq 0.2$ in the bivariable logistic regression analysis. Before running the above-specified model, we performed different diagnostic tests, particularly model fitness via Hosmer and Lemeshow test, multicollinearity, and sample size sufficiency. We assessed the strength of the association between the outcome variable (cost of illness of Epilepsy) and the independent variables using the Crude Odds Ratio (COR) and Adjusted Odds Ratio (AOR) that controls for other predictor variables in a model, 95\% CI. Finally, variables with a p-value of $<0.05$ in the multivariable analysis were considered statistically significant.

\section{Results \\ Socio-Demographic and Economic Characteristics of the Respondents}

A total of 422 epilepsy patients participated in the study with a response rate of $95.5 \%$. Of the total 422 respondents, $59.0 \%$ were males, more than $95 \%$ were of Amhara ethnicity, more than $85 \%$ were Orthodox Christian, $49.1 \%$ were single, and $33.2 \%$ attended secondary school. Nearly $75 \%$ of the patients were residing in urban areas.

The study indicated that the mean age, and the mean family size, and the mean monthly income of the patients were $32 \pm 11$ years, $4 \pm 2$, and US\$ 66.77, respectively. For $325(77.0 \%)$ patients, the distance from residence to the clinic was $\leq 20 \mathrm{~km}$. Almost all (99\%) patients used transportation means to travel to the hospital, and nearly all (98\%) patients used public transportations to travel to the hospital (Table 1).

\section{Clinical Characteristics of Study Participants}

The average frequency of the outpatient visits of the participants was $6 \pm 3$ times per year. Twelve percent of patients had been admitted to the hospital over the previous 12 months. The average duration of hospital stay was 1 \pm 1 day. Most patients (36\%) visited the hospital with at least one complaint.

Beyond the hospital's health care, some patients (34\%) used alternative health services, including traditional medicines. Seventy-eight percent of patients received care 
Table I Socio-Demographic and Economic Characteristics of Study Participants in Outpatient Department of the University of Gondar Referral Hospital, Northwest Ethiopia, 2018 ( $n=422$ )

\begin{tabular}{|c|c|c|}
\hline Variable & Frequency & Percent \\
\hline \multicolumn{3}{|l|}{ Sex } \\
\hline Male & 249 & 59.0 \\
\hline Female & 173 & 41.0 \\
\hline \multicolumn{3}{|l|}{ Marital status } \\
\hline Single & 207 & 49.1 \\
\hline Married & 164 & 38.9 \\
\hline Divorced & 30 & 7.1 \\
\hline Widowed & 16 & 3.8 \\
\hline Separated & 5 & 1.2 \\
\hline \multicolumn{3}{|l|}{ Ethnicity $(n=42 I)$} \\
\hline Amhara & 393 & 95.6 \\
\hline Tigrie & 16 & 3.9 \\
\hline Agaw & 2 & 0.5 \\
\hline \multicolumn{3}{|l|}{ Religion } \\
\hline Orthodox Tewahdo & 361 & 85.6 \\
\hline Muslim & 49 & 11.6 \\
\hline Protestant & 12 & 2.8 \\
\hline \multicolumn{3}{|l|}{ Educational status $(n=415)$} \\
\hline No formal education & $|3|$ & 31.6 \\
\hline Primary (Grade I -6) & 47 & 11.3 \\
\hline Secondary (Grade 7-12) & 138 & 33.2 \\
\hline College/University & 99 & 23.9 \\
\hline \multicolumn{3}{|l|}{ Occupation $(n=414)$} \\
\hline Unemployed & 73 & 17.6 \\
\hline Student & 63 & 15.2 \\
\hline Farmer & 60 & 14.5 \\
\hline Government employee & 58 & 14.0 \\
\hline Housewife & 54 & 13.0 \\
\hline Merchant & 38 & 9.2 \\
\hline Private employee & 34 & 8.2 \\
\hline Daily laborer & 23 & 5.6 \\
\hline Other & II & 2.7 \\
\hline \multicolumn{3}{|l|}{ Residence } \\
\hline Urban & 316 & 74.9 \\
\hline Rural & 106 & 25.1 \\
\hline \multicolumn{3}{|l|}{ Distance from residence to hospital } \\
\hline$\leq 20 \mathrm{~km}$ & 32,597 & 77.0 \\
\hline$>20 \mathrm{~km}$ & & 23.0 \\
\hline
\end{tabular}

from their family members at home. In addition to getting help from family members, $7 \%$ of patients also received a home care service from health professionals. The average loss of working days related to medical visits of Epilepsy amounted to $15 \pm 8$ days.
The average disease duration of study participants was $9 \pm 5$ years. The mean seizure frequency during the past year was $4 \pm 4$ times. Nearly thirty percent of patients took poly-therapy for the last 12 months. The majority of patients $(88.4 \%)$ got their medications from governmental pharmacies, and $53.3 \%$ had experienced at least one injury over the past year. Abrasion (38\%) and head injury $(29.8 \%)$ were the most frequent consequences of Epilepsy (Table 2).

\section{Cost of Epilepsy Among Study Participants}

The total annual cost per patient was US\$166 $\pm 61.6(95 \%$ CI: $158.5,170)$. From the total patients, $30 \%$ of patients incurred a high cost ( $\geq 40 \%$ of their annual income) due to Epilepsy. The study also revealed that the direct cost represented $27 \%$ (22\% for direct medical costs and 5\% for direct non-medical costs), and indirect costs $73 \%$ of the total cost of illness of Epilepsy.

\section{Direct Costs of Epilepsy}

The mean direct cost of illness of Epilepsy was US\$ $45 \pm 32$. The direct medical costs of Epilepsy which the patients incurred due to expenditures for consultation, medication, and screening (including diagnostic tests), averaged approximately US $\$ 37( \pm 27.3)(95 \%$ CI: $33,38.5)$ per year per patients. The costs of AED (US\$21.5) and investigations (US\$12.4) were the two primary contributors to the direct medical costs of Epilepsy. The direct non-medical costs were much less than direct medical care costs, averaged approximately US $\$ 8 \pm 9$ (95\% CI: 6.7, 8.5), in which expenses for transportation (US\$5.4) took the highest portion (Table 3).

\section{Indirect Costs of Epilepsy}

The total indirect cost per patient was US $\$ 120 \pm 53$. The study indicated that patients were not performing their normal daily activities for an average of $14 \pm 7$ days; as a result, the mean loss of income was US\$ $12 \pm 18$ for economically active patients. At least one caretaker, such as a family member or relative, accompanied a patient. The caretakers reported an average loss of $6 \pm 7$ workdays by the time they were accompanying the patient. Hence, the mean loss of income for caretakers was US $\$ 54 \pm 52$ who accompanied the patients. Costs due to loss of productivity averaged approximately US\$ 67 , which covered the highest portion (55.6\%) of indirect costs (Table 4). 
Table 2 Clinical Characteristics of Epileptic Patients in Outpatient Department of the University of Gondar Referral Hospital, Northwest Ethiopia, $2018(n=422)$

\begin{tabular}{|c|c|c|c|}
\hline Clinical Characteristics & Frequency & Number & Mean (SD) \\
\hline \multicolumn{4}{|l|}{ Place of Health Service Utilization } \\
\hline University of Gondar Referral Hospital & 289 & 68.5 & \\
\hline Other places & 133 & 31.5 & \\
\hline \multicolumn{4}{|c|}{ Types of other places for health service utilization $(n=133)$} \\
\hline Governmental health service & 15 & 11.2 & \\
\hline Private health service & 59 & 44.4 & \\
\hline Traditional healer & 59 & 44.4 & \\
\hline Disease duration & & & $9(5)$ \\
\hline I-5 years & $17 \mid$ & 40.5 & \\
\hline $6-10$ years & 105 & 24.9 & \\
\hline$>$ II years & 146 & 34.6 & \\
\hline Seizure frequency & & & $3.6(3.7)$ \\
\hline$<1$ per year & 109 & 25.8 & \\
\hline 2-11 per year & 274 & 64.9 & \\
\hline$>12$ per year & 39 & 9.3 & \\
\hline \multicolumn{4}{|l|}{ Number of AED } \\
\hline Mono-therapy & 294 & 69.7 & \\
\hline Poly-therapy & 128 & 30.3 & \\
\hline \multicolumn{4}{|c|}{ Place where patients buy anti-epileptic drugs $(n=421)$} \\
\hline Private drug store & 49 & 11.6 & \\
\hline Governmental drug store & 372 & 88.4 & \\
\hline \multicolumn{4}{|l|}{ Injury $(n=342)$} \\
\hline Burn & 17 & 5.0 & \\
\hline Abrasion & 164 & 48.0 & \\
\hline Dental injury & 37 & 10.8 & \\
\hline Head injury & 102 & 29.8 & \\
\hline Dislocation & 22 & 6.4 & \\
\hline
\end{tabular}

\section{Factors Affecting the Cost of Illness of Epilepsy}

The study indicated that age, sex, educational status, number of AED, seizure frequency, drug store, and disease duration were factors significantly associated with the cost of illness of Epilepsy, having a p-value of $\leq 0.05$ (Table 5).

The study showed that female patients were 3.66 (AOR $=3.66 ; 95 \%$ CI: $1.94,6.89)$ times more likely to incur the high cost of Epilepsy than male patients. The age of patients was also another factor that was significantly associated with the high cost of Epilepsy. As the patient's age increased by one year, the likelihood to incur high costs increased by $4 \%(\mathrm{AOR}=1.04 ; 95 \% \mathrm{CI}: 1.03,1.09)$.

Patients who attended primary education were $75 \%$ $(\mathrm{AOR}=0.25 ; 95 \% \mathrm{CI}: 0.08,0.70)$ less likely to incur high cost than patients with no formal education. Patients who attended secondary education were 89\% (AOR = $0.11 ; 95 \% \mathrm{CI}=0.05,0.26$ ) less likely to incur high cost compared to patients with no formal education. Patients who joined college or university were $85 \%(A O R=0.15$; 95\% CI: 0.005-0.047) less likely to incur high cost than patients with no formal education.

For patients who experienced two to 11 seizures per year, the likelihood to incur high cost increased by 2.37 (AOR = 2.37; 95\% CI: 1.07-5.22) times compared to those who experienced less than one seizure. Besides, for patients who experienced more than 12 seizures per year, the likelihood to incur high cost increased by 4.48 (AOR $=4.48$; $95 \% \mathrm{CI}=1.56,12.8)$ times compared to those who experienced less than one seizure. The study also predicted that 
Table 3 Direct Cost of Epilepsy on Study Participants in Outpatient Department of the University of Gondar Referral Hospital, Northwest Ethiopia, $2018(n=422)$

\begin{tabular}{|l|l|}
\hline Types of Cost & Mean (SD) Cost in ETB \\
\hline $\begin{array}{l}\text { Direct medical cost } \\
\text { Consultation fee } \\
\text { Medication fee } \\
\text { Investigation fee } \\
\text { Total medical cost }\end{array}$ & $78.8(54.4)$ \\
$584.9(351.5)$ \\
\hline $\begin{array}{l}\text { Direct non-medical cost } \\
\text { Transportation }\end{array}$ & $339(474.5)$ \\
Food and accommodation & $1009.6(743.6)$ \\
Total non-medical cost & $148(176.4)$ \\
\hline Total direct cost & $61.5(126.6)$ \\
\hline
\end{tabular}

Note: Key: I US\$ $=27.24$ ETB.

Table 4 Indirect Cost of Epilepsy on Study Participants in Outpatient Department of the University of Gondar Referral Hospital, Northwest Ethiopia, 2018 ( $n=422)$

\begin{tabular}{|l|c|}
\hline Variables & $\begin{array}{c}\text { Mean (Standard } \\
\text { Deviation) }\end{array}$ \\
\hline Number of attendants per patient & $\mathrm{I}(\mathrm{I})$ \\
Workdays lost by attendants & $6(7)$ \\
Numbers of visits & $6(3)$ \\
Workdays lost by patients & $14(34)$ \\
Loss of income; patients & $323(503)$ \\
Loss of income; working attendants & $1459(1403)$ \\
Lost productivity & $1819(1487)$ \\
Total indirect cost & $\mathbf{3 2 6 8 . 8 ( 1 4 3 1 . 9 )}$ \\
\hline
\end{tabular}

Note: Key: I US\$ $=27.24$ ETB.

those who took two or more medications at a time were 4.66 $(\mathrm{AOR}=4.66 ; 95 \% \mathrm{CI}: 2.29,9.46)$ times more likely to incur high cost than those who took only one drug.

For those who bought drugs from private stores, the likelihood to incur high costs increased by 6.23 times $(\mathrm{AOR}=6.23 ; 95 \% \mathrm{CI}: 2.76,14.03)$ compared to patients who bought drugs from governmental stores.

For patients with disease duration of 6 up to 10 years, the likelihood to incur high cost decreased by 61\% (AOR $=0.39 ; 95 \% \mathrm{CI}: 0.18,0.85)$ compared to patients with less than five years of disease duration. For patients with a disease duration of 10 years and above, the likelihood to incur high cost decreased by $89 \%$ (AOR $=0.11 ; 95 \%$ CI: $0.05,0.25)$ compared to patients with less than five years of disease duration.

\section{Discussion}

This study showed that the overall mean cost of illness of Epilepsy was US\$ $166 \pm 61.6$. This finding is in-line with an Indian study ${ }^{24}$ but higher than the cost incurred among epilepsy patients in Burundi, which was (US\$48.4) ${ }^{13}$ and Bhutan (US\$ 91), ${ }^{21}$ and lower than a study done in India (US\$ 344) ${ }^{16}$ and China (US\$ 949). ${ }^{20}$ The possible explanation for the variation in cost may be due to the difference in the health care setting and method used.

The mean direct medical cost was US\$ $32.4 \pm 18.83$. This finding is consistent with a study conducted in Bhutan (US\$42) ${ }^{21}$ but lower than a study conducted in South Africa (US\$ 58) ${ }^{25}$ and China (US\$372): ${ }^{20}$ this may be due to the difference in availability of advanced medical equipment. The direct non-medical cost was US\$ 7.7 \pm 9 , which is similar to an Indian study (US\$ 16). ${ }^{16}$ The composition of direct costs shared certain similarities with the costs of AED accounted for the most part. ${ }^{20,26}$

The indirect cost of Epilepsy was US\$ $120 \pm 53$, which is lower than a study finding in China (US\$276). ${ }^{20}$ This discrepancy may be due to the difference in the per capita income of the countries.

In this study, the indirect cost constituted $73 \%$ of the overall total cost, which is comparable to the result found in Burundi $(75.8 \%)^{13}$ and India $(72.9 \%){ }^{20}$

Female patients were 3.66 times more likely to incur the high cost of Epilepsy compared to male patients. This variation may be due to female patients who tend to visit clinics more frequently and consume more health care than male patients. They also get more social support than male patients. They mostly came with one or more companions. However, this finding contradicts a study conducted in Oman $^{17}$ and China ${ }^{20}$ that concluded that epilepsy patients' cost is equal for both sexes. This contradiction may be due to economic similarities between both sexes.

The patient's age was also another factor significantly associated with the high cost of Epilepsy. As the patient's age increased by one year, the likelihood to incur high costs increased by $4 \%$. Even if the results were not directly comparable due to the difference in model use, a study conducted in China, ${ }^{20}$ Bhutan, ${ }^{21}$ and Oman ${ }^{17}$ support this finding. This similarity among the findings might be due to high health care seeking by elderly patients because of a relatively high health risk as age increases. Increased age also leads to vulnerability to injuries responsible for the increased cost of health care in hospitalization and medical intervention. 
Table 5 Factors Associated with Cost of Illness of Epilepsy of Study Participants in Outpatient Department of the University of Gondar Referral Hospital, Northwest Ethiopia, 2018 ( $n=422)$

\begin{tabular}{|c|c|c|c|c|c|}
\hline \multirow[t]{2}{*}{ Variables } & \multicolumn{2}{|c|}{ Cost of IIIness } & \multirow[t]{2}{*}{ COR $(95 \% \mathrm{Cl})$} & \multirow[t]{2}{*}{ AOR $(95 \% \mathrm{Cl})$} & \multirow[t]{2}{*}{ P-value } \\
\hline & High & Low & & & \\
\hline \multicolumn{6}{|l|}{ Sex } \\
\hline Male & 52 & 197 & 1 & I & \\
\hline Female & 76 & 97 & $2.96(1.93-4.56)$ & $3.66(1.94-6.89)$ & $0.000 * * *$ \\
\hline Age & & & $1.06(1.04-1.08)$ & $1.04(1.03-1.09)$ & $0.001 * * *$ \\
\hline \multicolumn{6}{|l|}{ Marital status } \\
\hline Single/Not married & 66 & 192 & 1 & 1 & \\
\hline Married & 62 & 162 & $0.56(0.37-0.86)$ & $0.86(0.4|-| .78)$ & 0.684 \\
\hline \multicolumn{6}{|l|}{ Educational status } \\
\hline No formal education & 78 & 53 & I & I & \\
\hline Primary education & 14 & 33 & $0.28(0.14-0.59)$ & $0.25(0.08-0.70)$ & $0.009 * *$ \\
\hline Secondary education & 26 & 112 & $0.16(0.09-0.27)$ & $0.11(0.05-0.26)$ & $0.000 * * *$ \\
\hline College/University & 7 & 92 & $0.05(0.02-0.12)$ & $0.15(0.005-0.05)$ & $0.000 * * *$ \\
\hline Family size & & & $1.09(0.97-1.23)$ & $0.95(0.77-1.16)$ & 0.605 \\
\hline \multicolumn{6}{|l|}{ Residence } \\
\hline Urban & 91 & 225 & 1 & 1 & \\
\hline Rural & 37 & 69 & $1.33(0.83-2.11)$ & $0.78(0.26-2.40)$ & 0.667 \\
\hline \multicolumn{6}{|l|}{ Distance } \\
\hline$\leq 20 \mathrm{~km}$ & 88 & 237 & I & I & \\
\hline$>20 \mathrm{~km}$ & 40 & 57 & $1.89(1.18-3.03)$ & $1.56(0.44-5.56)$ & 0.485 \\
\hline \multicolumn{6}{|l|}{ Number of drugs } \\
\hline Mono-therapy & 68 & 226 & 1 & 1 & \\
\hline Poly-therapy & 60 & 68 & $2.93(1.88-4.55)$ & $4.66(2.29-9.46)$ & $0.000 * * *$ \\
\hline \multicolumn{6}{|l|}{ Seizure frequency } \\
\hline$<1 /$ year & 18 & 104 & $\mathrm{I}$ & I & \\
\hline $2-11 /$ year & 84 & 162 & $2.99(1.70-5.27)$ & $2.37(1.07-5.22)$ & $0.000 * * *$ \\
\hline$\geq 12 /$ year & 26 & 28 & $5.36(2.58-11.15)$ & $4.48(1.56-12.8)$ & $0.000 * * *$ \\
\hline \multicolumn{6}{|l|}{ Place where patients buy AEDs } \\
\hline Government drug store & 85 & 263 & I & 1 & \\
\hline Private drug store & 43 & 30 & $4.43(2.62-7.50)$ & $6.23(2.76-14.03)$ & $0.000 * * *$ \\
\hline \multicolumn{6}{|l|}{ Disease duration } \\
\hline $\mathrm{I}-5$ years & 67 & 80 & 1 & 1 & \\
\hline $6-10$ years & 32 & 70 & $0.55(0.32-0.93)$ & $0.39(0.18-0.85)$ & $0.019 *$ \\
\hline$>10$ years & 29 & 144 & $0.24(0.14-0.40)$ & $0.1 \mathrm{I}(0.05-0.25)$ & $0.000 * * *$ \\
\hline
\end{tabular}

Notes: ***Significant with $\mathrm{p}$-value $\leq 0.001$; $* *$ significant with $\mathrm{p}$-value $\leq 0.01$; $*$ significant with $\mathrm{p}$-value $\leq 0.05$.

Abbreviations: COR, crude odds ratio; AOR, adjusted odds ratio.

This study also showed that patients who attended higher education were $85 \%$ less likely to incur high costs than patients with no formal education. This variation may be due to awareness, prevention, and early detection of risk factors. People with high education are more likely to learn about healthy behaviors and understand their health needs, follow instructions and communicate effectively with health providers.

For patients who experienced two to 11 seizures per year, the likelihood to incur high costs increased by 2.37 times compared to those who experienced less than one seizure. Besides, for patients who experienced more 
than 12 seizures per year, the likelihood to incur high costs increased by 4.48 times compared to those who experienced less than one seizure. This finding is congruent with the study findings in China ${ }^{20}$ and Bhutan. ${ }^{21}$ This similarity may be because frequent seizure needs additional treatment and care. For patients who have lived with the disease for six to 10 years, the likelihood to incur high costs decreased by $61 \%$ compared to patients who have lived with the disease for less than five years. Besides, for patients who have lived with the disease for more than ten years, the likelihood to incur high costs decreased by $89 \%$ compared to patients who have lived with the disease for less than five years. This finding is in line with studies done in $\mathrm{China}^{20}$ and Germany. ${ }^{27}$ This similarity may be because medical costs are higher for newly diagnosed Epilepsy due to greater diagnostic procedures at the onset.

In contrast, during follow-up, costs decrease as the need for diagnostic evaluations declines and some patients have discontinued their treatment. The model also predicted that those who took two or more medications at once were 4.66 times more likely to incur high costs than those who took only one drug. This finding is consistent with a study in Bhutan ${ }^{21}$ and China. ${ }^{20}$ This consistency may be due to the high cost of AED's.

For those who bought drugs from private stores, the likelihood to incur high costs increased by 6.23 times than patients who bought drugs from governmental stores. This variation may occur because private stores' main objective is maximizing their profit.

\section{Limitations of the Study}

This study did not measure intangible costs, and accurate income assessment was difficult; some income may be in cash while others are in kind. Subjects also may not genuinely report their income. This study relied on participants' self-report of costs, so difficulties in recalling costs incurred may underestimate our result.

\section{Conclusion}

The total annual cost of illness of Epilepsy per patient was high, especially taking into account the per capita of the Ethiopian citizens. The study also indicated that nearly onethird of the patients faced catastrophic effects due to epilepsy-related costs. The cost of illness of Epilepsy was affected by the age, sex, and educational status of the patients; and the number of AED, seizure frequency, places where patients buy drugs, and disease duration. Hence, creating an alternative source of income, socio-economic support, and affordable health care service for patients, especially for female and elderly patients, and strengthening and equipping nearby clinics to provide epilepsy-related services are essential. Increasing drug availability in governmental pharmacies, developing and implementing epilepsy education programs, availing data about Epilepsy, engaging concerned bodies in the planning and implementation of Epilepsy prevention and control programs could also be some of the strategies to minimize the catastrophic effect of Epilepsy.

\section{Data Sharing Statement}

The datasets used and/or analyzed during this study are available from the corresponding authors on reasonable request.

\section{Ethics Approval and Consent to Participate}

This study was conducted in accordance with the Declaration of Helsinki. We obtained the ethical clearance for the research from the Ethical Review Board of the Institute of Public Health, University of Gondar. We took verbal consent from each study participant after a brief explanation and full disclosure of the benefit or risk in participating in the study, which was approved by the Ethical Review Board. We also informed the participant that they could quit participating in the research at any time they want. We assured confidentiality by removing identifiers and locking the questionnaires after data collection.

\section{Consent for Publication}

Not applicable

\section{Acknowledgments}

We would like to thank the Institute of Public Health, University of Gondar, for proper review and approval for this research paper. Our deepest gratitude goes to the UoGRH for their permission to do this research project. We would like to thank the study participants and the data collectors, and supervisors for their valuable cooperation during the data collection period.

\section{Author Contributions}

All authors contributed to data analysis, drafting or revising the article, have agreed on the journal to which the article will be submitted, gave final approval of the version 
to be published, and agree to be accountable for all aspects of the work.

\section{Authors' Information}

PM is a Health Economist at the UoGRH, Ethiopia. YA is a Lecturer at the Department of Epidemiology and Biostatistics, Institute of Public Health, College of Medicine and Health Sciences, University of Gondar, Ethiopia. AM is a Lecturer at the Department of Health Systems and Policy, Institute of Public Health, College of Medicine and Health Sciences, University of Gondar, Ethiopia. AA is an Assistant professor at the Department of Health Systems and Policy, Institute of Public Health, College of Medicine and Health Sciences, University of Gondar, Ethiopia. MY is an Associate Professor of Health Management and Health Economics at the Department of Health Systems and Policy, Institute of Public Health, College of Medicine and Health Sciences, University of Gondar, Ethiopia.

\section{Funding}

No funding was received for this study.

\section{Disclosure}

The authors declare that they have no conflicts of interest for this work.

\section{References}

1. De Boer HM. "Out of the shadows": a global campaign against Epilepsy. Epilepsia. 2002;43(p):7-8. doi:10.1046/j.1528-1157.43. s.6.4.x

2. World Health Organization. Mental health: new understanding, new hope. The world health report; 2001.

3. De Boer HM, Mula M, Sander JW. The global burden and stigma of Epilepsy. Epilepsy Behav. 2008;12(4):540-546. doi:10.1016/j. yebeh.2007.12.019

4. Kale R. Bringing Epilepsy out of the shadows. BMJ. 1997;315 (7099):2. doi:10.1136/bmj.315.7099.2

5. Kotsopoulos IA, Evers SMAA, Ament AJHA, et al. Estimating the costs of Epilepsy: an international comparison of epilepsy cost studies. Epilepsia. 2001;42(5):634-640. doi:10.1046/j.1528-1157.2001.18200.x

6. Begley CE, Beghi E. The economic cost of Epilepsy: a review of the literature. Epilepsia. 2002;43(p):3-9. doi:10.1046/j.1528-1157.43.s.4.2.x

7. Donker G, Foets M, Spreeuwenberg P. Epilepsy patients: health status and medical consumption. $J$ Neurol. 1997;244(6):365-370. doi:10.1007/s004150050103

8. Wiebe S, Eliasziw M, Bellhouse DR, et al. Burden of Epilepsy: the Ontario health survey. Canadian J Neurol Sci. 1999;26(4):263-270. doi:10.1017/S0317167100000354

9. Reid AY, Metcalfe A, Patten SB, et al. Epilepsy is associated with unmet health care needs compared to the general population despite higher health resource utilization-A Canadian population-based study. Epilepsia. 2012;53(2):291-300. doi:10.1111/j.1528-1167.2011.03353.x
10. Zachry WM III, Doan QD, Smith BJ, et al. Direct medical costs for patients seeking emergency care for losses of epilepsy control in a US managed care setting. Epilepsy Behav. 2009;16(2):268-273. doi:10.1016/j.yebeh.2009.07.042

11. Jacoby A, Buck D, Baker G, et al. Uptake and costs of care for Epilepsy: findings from a UK regional study. Epilepsia. 1998;39 (7):776-786. doi:10.1111/j.1528-1157.1998.tb01164.x

12. Epilepsy GCA. Epilepsy in the WHO African Region: bridging the gap. Brazzaville: World Health Organization Regional Office for Africa; 2004.

13. Nsengiyumva G. Economic evaluation of Epilepsy in Kiremba (Burundi): a case-control study. Epilepsia. 2004;45(6):673-677. doi:10.1111/j.0013-9580.2004.36303.x

14. Lagunju I, Imam Z, Adedokun B. Cost of Epilepsy in children attending a tertiary centre in Nigeria. Int Health. 2011;3 (3):213-218. doi:10.1016/j.inhe.2011.07.001

15. Verguet S, Memirie ST, Norheim OF. Assessing the burden of medical impoverishment by cause: a systematic breakdown by disease in Ethiopia. BMC Med. 2016;14(1):164. doi:10.1186/s12916-016-0697-0

16. Thomas S, Sarma PS, Alexander M, et al. Economic burden of Epilepsy in India. Epilepsia. 2001;42(8):1052-1060. doi:10.1046/ j.1528-1157.2001.0420081052.x

17. Al-Zakwani I, Hanssens Y, Deleu D, et al. Annual direct medical cost and contributing factors to total cost of Epilepsy in Oman. Seizure. 2003;12(8):555-560. doi:10.1016/S1059-1311(03)00068-2

18. Riechmann J, Strzelczyk A, Reese JP, et al. Costs of Epilepsy and cost-driving factors in children, adolescents, and their caregivers in Germany. Epilepsia. 2015;56(9):1388-1397. doi:10.1111/epi.13089

19. Academy of Science of South Africa. Proceedings report Changing patterns of Non-Communicable Diseases; 2013. Available from: https://research.assaf.org.za/handle/20.500.11911/53.

20. Gao L, Xia L, Pan S-Q, et al. Burden of Epilepsy: a prevalence-based cost of illness study of direct, indirect and intangible costs for Epilepsy. Epilepsy Res. 2015;110(p):146-156. doi:10.1016/j. eplepsyres.2014.12.001

21. Wibecan L, Fink G, Tshering L, et al. The economic burden of Epilepsy in Bhutan. Trop Med Int Health. 2018;23(4):342-358. doi:10.1111/tmi.13035

22. Van Hout B, Gagnon D, Souetre E, et al. Relationship between seizure frequency and costs and quality of life of outpatients with partial Epilepsy in France, Germany, and the United Kingdom. Epilepsia. 1997;38(11):1221-1226. doi:10.1111/j.1528-1157.1997. tb01220.x

23. Xu K. World Health Organization. Distribution of health payments and catastrophic expenditures methodology. Geneva: World Health Organization; 2005.

24. Krishnan A, Sahariah SUA, Kapoor SK. Cost of Epilepsy in patients attending a secondary-level hospital in India. Epilepsia. 2004;45 (3):289-291. doi:10.1111/j.0013-9580.2004.63102.x

25. Wagner RG, Bertram MY, Gómez-Olivé FX, et al. Health care utilization and outpatient, out-of-pocket costs for active convulsive epilepsy in rural northeastern South Africa: a cross-sectional Survey. BMC Health Serv Res. 2016;16(1):208. doi:10.1186/s12913-016$1460-0$

26. Jung J, Seo H-Y, Kim YA, et al. The economic burden of Epilepsy in Korea, 2010. J Prevent Med Public Health. 2013;46(6):293. doi:10.3961/jpmph.2013.46.6.293

27. Hamer HM, Spottke A, Aletsee C, et al. Direct and indirect costs of refractory Epilepsy in a tertiary epilepsy center in Germany. Epilepsia. 2006;47(12):2165-2172. doi:10.1111/j.15281167.2006.00889.x 


\section{Publish your work in this journal}

Risk Management and Healthcare Policy is an international, peerreviewed, open access journal focusing on all aspects of public health, policy, and preventative measures to promote good health and improve morbidity and mortality in the population. The journal welcomes submitted papers covering original research, basic science, clinical \& epidemiological studies, reviews and evaluations, guidelines, expert opinion and commentary, case reports and extended reports. The manuscript management system is completely online and includes a very quick and fair peer-review system, which is all easy to use. Visit http://www.dovepress.com/testimonials.php to read real quotes from published authors. 